\title{
Genetic View To Stroke Occurrence
}

\author{
Sadegh Yoosefee ${ }^{1 *}$, Seyyed Amir Hejazi ${ }^{1}$, Ehsan Sharifipour ${ }^{1}$, Tayyebeh Sabokbar $^{1}$ \\ ${ }^{1}$ Neurology and Neuroscience Research Center, Qom University of M edical Sciences, Qom, Iran. \\ *Corresponding Author: Email: Yoosefee@gmail.com.
}

Stroke is the third leading cause of death. The role of genetics in the etiology and development of this disease is undeniable. As a result of inadequate previous research, more and more studies in the field of genetics are necessary to identify pathways involved in the pathogenesis of stroke, which in turn, may lead to new therapeutic approaches. However, due to the multifactorial nature of stroke and the few studies conducted in this field, genetic diversity is able to predict only a small fraction of the risk of disease. On the other hand, studies have shown genetically different architecture for different types of stroke, and finally pharmacogenomics as an important part of personalized medicine approach, is influenced by genetic studies, all of which confirm the need of addressing the topic by researchers.

Key words: stroke; genetics; genetic diversity

DOI: $10.7575 /$ aiac.abcmed.ca1.75

Published Date: February 2017

Peer-review is under responsibility of the 9th Iranian Stroke Congress.

Published by Australian International Academic Centre, Australia

This published work is open access under the CC BY license.

Available online at www.abcmed.aiac.org.au 